\title{
Growth Hormone Excess
}

National Cancer Institute

\section{Source}

National Cancer Institute. Growth Hormone Excess. NCI Thesaurus. Code C112834.

Overproduction of growth hormone, a protein-based peptide that stimulates growth, cell reproduction, and cell regeneration. 